Araştırma Makalesi - Research Article

\title{
Dünya Bankası Reel Verileri İle Gayri Safi Yurtiçi Hasıla Modeline Conformable Türev Yaklaşımı
}

\author{
Ramazan Özarslan ${ }^{1 *}$
}

ÖZ

Revize / Revised: 25/03/2020

Kabul / Accepted: 13/04/2020

$\mathrm{Bu}$ çalışmada, conformable türev yardımıyla gayri safi yurtiçi hasıla (GSYİH) modelini ele alıyoruz. Conformable GSYİH modelinin analitik çözümünü elde ediyor ve sonuçları, 1960-2018 yılları arasında Dünya Bankası'ndan [20] alınan Kore Cumhuriyeti, Avrupa Birliği ve Amerika Birleşik Devletleri'nin reel verilerini göz önüne alarak tam mertebeden GSYİH modeliyle, simülasyonlar ve hata analizleri yardımıyla karşılaştırıyoruz. 


\title{
Conformable Derivative Approach to Gross Domestic Product Model with Real Data of World Bank
}

\begin{abstract}
In this study, we consider gross domestic product (GDP) model within conformable derivative. In view of real data from the Republic of Korea, the European Union and the United States of America taken from World Bank [20] between 1960-2018 by simulations and error analysis, we obtain an analytical solution of the conformable GDP model and compare the findings with the integer order GDP model.
\end{abstract}

Keywords- Conformable derivative, Gross domestic product model, Real data, Error analysis 


\section{INTRODUCTION}

Conformable derivative was firstly defined by Khalil et al. [1]. This newly defined derivative is a local derivative and a different type of ordinary derivative. Conformable derivative of order $\alpha$ is defined by,

$$
T_{a}^{\alpha} f(t)=\lim _{\varepsilon \rightarrow 0} \frac{f\left(t+\varepsilon t^{1-\alpha}\right)-f(t)}{\varepsilon} .
$$

However, it has similar properties with ordinary derivative. Some of them are the product derivative of two functions and the quotient derivative of two functions. The fact that conformable derivative exhibits similar properties to the ordinary derivative has attracted the attention of many scientists. Abdeljawad [2], Atangana et al.[3] made the first studies about conformable derivatives. Some of the Conformable Derivative Applications are given by [4-6].

Another conformable derivative definition was given by Katugampola [7]. It is defined as;

$$
T_{a}^{\alpha} f(t)=\lim _{\varepsilon \rightarrow 0} \frac{f\left(t e^{\varepsilon t^{-\alpha}}\right)-f(t)}{\varepsilon} .
$$

It was analyzed in detail by Anderson and Ulness [8]. This type of conformable derivative has the same properties as the conformable derivative mentioned above.

Mathematical models are used to determine the future of the systems in the real world. Ordinary derivative of the first order defines the rate of change in time.

Due to this new characteristic property of the ordinary derivative, it is used to establish fundamental mathematical models such as linear and exponential, but in recent years new types of derivatives have been established, some of them being Caputo, Atangana-Baleanu [9], Caputo-Fabrizio [10], conformable[1-3] etc. With this new type of derivatives, mathematical models with ordinary derivatives were reconsidered and the aim was to fit real data, and hence to be able to predict the future of real world applications more accurately than integer order equivalents, cf. [11-19].

The Gross Domestic Product (GDP) is the total number of goods produced in a country and indicates the economic growth of the country. It is considered to determine the economic standard of living of a country. GDP enables increases or declines in the amount of economic output over various times to be evaluated.

The mathematical model of GDP determines a country's economic growth rate. It is given in the following form,

$$
S^{\prime}(t)=k S(t)
$$

In this study, we consider the GDP model using conformable derivative with real data from the Republic of Korea, European Union and the United States from the World Bank [20] between the years 19602018. We compare the classical GDP model with conformable derivative by using real data. Results show that for the GDP model on fitting real data, conformable derivative is more successful than an integer order counterpart.

\section{PRELIMINARIES}

We give some necessary notations, definitions and lemmas related to conformable theory, cf. [1, 2, 8].

Definition 2.1. [1,2] Let $f:(0, \infty) \rightarrow \square$ and $t>0$. Then the conformable derivative of $f$ of order $0<\alpha \leq 1$ is defined by, 


$$
T_{a}^{\alpha} f(t)=\lim _{\varepsilon \rightarrow 0} \frac{f\left(t+\varepsilon(t-a)^{1-\alpha}\right)-f(t)}{\varepsilon} .
$$

Theorem 2.2. [1] If a function $f:[0, \infty) \rightarrow \square$ is $\alpha$-differentiable at $a>0, \alpha \in(0,1]$, then $f$ is continuous at $a$.

Theorem 2.3. [1,2] Let $\alpha \in(0,1]$ and $f, g$ be $\alpha$-differentiable at $a$ point $t>0$. Then,

i. $\quad T_{a}^{\alpha}(C)=0$, for all constant functions, $f(t)=C$;

ii. $\quad T_{a}^{\alpha}\left(t^{n}\right)=n t^{n-\alpha}$ for all $n \in \square$;

iii. $\quad T_{a}^{\alpha}[a f+b g]=a T_{a}^{\alpha}[f]+b T_{a}^{\alpha}[g]$ for all $a, b \in \square$;

iv. $\quad T_{a}^{\alpha}[f g]=f T_{a}^{\alpha}[g]+g T_{a}^{\alpha}[f]$;

v. $\quad T_{a}^{\alpha}\left[\frac{f}{g}\right]=\frac{g T_{a}^{\alpha}[f]-f T_{a}^{\alpha}[g]}{g^{2}}$

vi. $\quad T_{a}^{\alpha}[f o g](t)=f^{\prime}(g(t)) T_{a}^{\alpha} g(t)$, for $f$ differentiable at $g(t)$.

If, in addition, $f$ is differentiable, then $T_{a}^{\alpha}(f)(t)=t^{1-\alpha} \frac{d f}{d t}(t)$.

Theorem 2.4. [1] Let $a, n \in \square$ and $\alpha \in(0,1]$. Then we have the following results.
i. $\quad T_{a}^{\alpha}(1)=0$,
ii. $\quad T_{a}^{\alpha}\left(e^{a x}\right)=a x^{1-\alpha} e^{a x}$,
iii. $\quad T_{a}^{\alpha}(\sin a x)=a x^{1-\alpha} \cos a x$,
iv. $T_{a}^{\alpha}(\cos a x)=-a x^{1-\alpha} \sin a x$,
v. $\quad T_{a}^{\alpha}\left(\frac{1}{\alpha} t^{a}\right)=1$.

It is easy to see from part (vi) of Theorem 2.3.

Theorem 2.5. [1] Let $\alpha \in(0,1]$ and $t>0$. Then,
i. $\quad T_{a}^{\alpha}\left(e^{\wedge} \frac{\lambda t^{\alpha}}{\alpha}\right)=\lambda e^{\wedge} \frac{t^{\alpha}}{\alpha}$
ii. $\quad T_{a}^{\alpha}\left(\sin \left(\frac{1}{\alpha} t^{\alpha}\right)\right)=\cos \left(\frac{1}{\alpha} t^{\alpha}\right)$,
iii. $\quad T_{a}^{\alpha}\left(\cos \left(\frac{1}{\alpha} t^{\alpha}\right)\right)=-\sin \left(\frac{1}{\alpha} t^{\alpha}\right)$. 
Theorem 2.6. [1] Let $\alpha \in(0,1)$ and $t>0$. Then, conformable integral is defined as follows

$$
\left(I_{a}^{\alpha} f\right)(x)=\int_{a}^{x} f(t) d_{\alpha}(t)=\int_{a}^{x} f(t)(t-a)^{\alpha-1} d t .
$$

\section{MAIN RESULTS}

In this section, we consider conformable GDP model with real data of Republic of Korea, European Union and the United States from World Bank [20] between the years 1960-2018, and we compare the classical GDP model with conformable derivative by using real data. We analyze results by means of error sum of squares (SSE).

$$
S S E=\sum_{i=1}^{n} \frac{\left(x_{i}-y_{i}\right)^{2}}{N}
$$

here $N$ is data number, $x_{i}$ is given real data and $y_{i}$ is estimated data obtained by differential models. Then, we analyze efficiency of models with residual sum of squares

$$
\text { Efficiency }=\frac{\sum_{i=1}^{n} x_{i}^{2}-\sum_{i=1}^{n} \varepsilon_{i}^{2}}{\sum_{i=1}^{n} x_{i}^{2}} \times 100
$$

here $\varepsilon_{i}$ is error margin. Results show that for the GDP model on fitting real data, conformable derivative is more efficient than an integer order counterpart.

\section{A. Gross Domestic Product Model With Conformable Derivative}

The GDP is one of the most important statistical methods for economical measurement determining the performance of countries' economy. If we consider GDP model within conformable derivative,

$$
T^{\alpha} S(t)=k S(t)
$$

then its analytical solution is given by

$$
S(t)=c e^{\wedge} \frac{k t^{\alpha}}{\alpha}
$$

Here $S(t)$ is the change in GDP in time, $c$ is a constant, $k$ is a constant which has a dimension of time $e^{-\alpha}$. We take into account real GDP data Republic of Korea, European Union and United States of America from World Bank [20] between the years 1960-2018.

\section{B. Discussions of Conformable Gross Domestic Product Model With Real Data}

In this section, we consider conformable GDP model (2) and integer order GDP model (1) with real data of Republic of Korea, European Union and United States of America from World Bank [20] between the years 1960-2018. Obtained results are compared with each other. Error analysis and efficiency of models are given in tables 1-2-3 and analytical solutions with optimum parameters are compared with real data in figures 12-3. Wolfram Mathematica 11 (Wolfram Research, Inc.) is used for calculations and simulations. 


\begin{tabular}{|c|c|c|}
\hline & $\begin{array}{l}\text { BŞEÜ Fen Bilimleri Dergisi } \\
7(1), 1-9,2020\end{array}$ & $\begin{array}{r}\text { BSEU Journal of Science } \\
\text { DOI: } 10.35193 / \text { bseufbd.640361 }\end{array}$ \\
\hline $\begin{array}{l}\text { BLLECEKSEYHEDEBAL } \\
\text { UNIVERSITESI }\end{array}$ & & 58-7575 (http://dergipark.gov.tr/bseufbd) \\
\hline
\end{tabular}

Table 1. Optimum parameters for GDP of Republic of Korea and error analysis

\begin{tabular}{lcccc}
\hline Republic of Korea & $\mathbf{k}$ & $\boldsymbol{\alpha}$ & $\mathbf{S S E}$ & Efficiency $(\%)$ \\
\hline Integer Order Model & 0.0936555 & & $1.56003 * 10^{\wedge} 7$ & 91.2547 \\
\hline Conformable Model & 0.303153 & 0.562142 & $3.00891 * 10^{\wedge} 6$ & 98.3132 \\
\hline
\end{tabular}

Table 2. Optimum parameters for GDP of European Union and error analysis

\begin{tabular}{lcccc}
\hline European Union & $\mathbf{k}$ & $\boldsymbol{\alpha}$ & SSE & Efficiency (\%) \\
\hline Integer Order Model & 0.0686138 & & $3.92886 * 10^{\wedge} 7$ & 90.0811 \\
\hline Conformable Model & 0.238716 & 0.523411 & $9.26742^{*} 10^{\wedge} 6$ & 97.6603 \\
\hline
\end{tabular}

Table 3. Optimum parameters for GDP of USA and error analysis

\begin{tabular}{lcccc}
\hline USA & $\mathbf{k}$ & $\boldsymbol{\alpha}$ & SSE & Efficiency (\%) \\
\hline Integer Order Model & 0.0543405 & & $3.49351 * 10^{\wedge} 7$ & 96.4515 \\
\hline Conformable Model & 0.140229 & 0.652009 & $5.31114 * 10^{\wedge} 6$ & 99.4605 \\
\hline
\end{tabular}
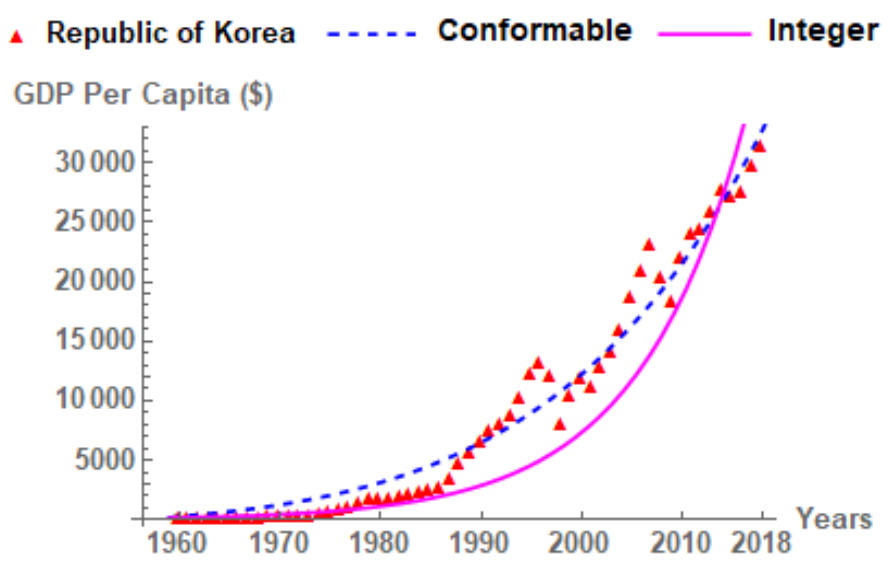

Figure 1. Comparison of models with real data of Republic of Korea

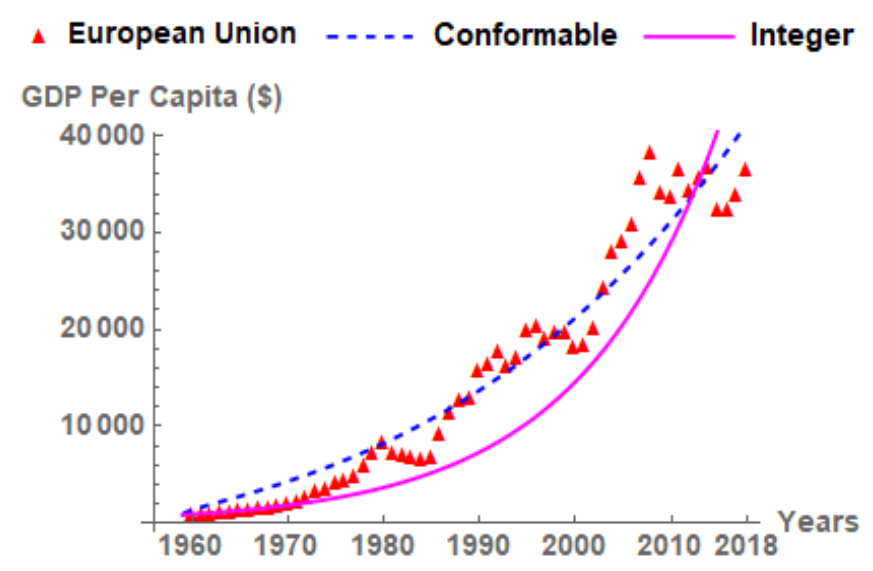

Figure 2. Comparison of models with real data of European Union 


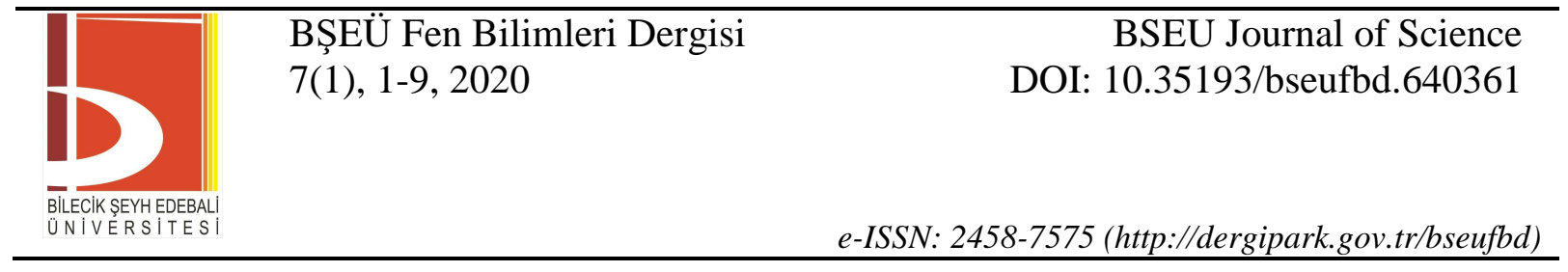

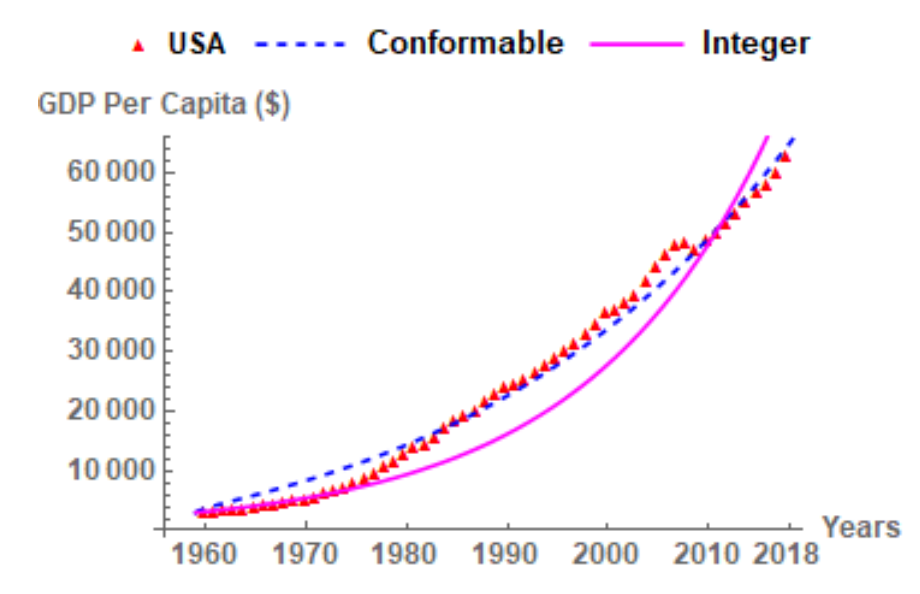

Figure 3. Comparison of models with real data of USA

Table 4. Comparison of models with real data by years

\begin{tabular}{cccccccccc}
\hline & \multicolumn{2}{c}{ Republic of Korea } & \multicolumn{3}{c}{ European Union } & \multicolumn{3}{c}{ USA } \\
\hline Years & Real Data & Conformable & Integer & Real Data & Conformable & Integer & Real Data & Conformable & Integer \\
\hline 1989 & 5736.9 & 5675.9 & 2392.1 & 22857.1 & 20766 & 14539.3 & 12835.7 & 12508 & 6415.2 \\
1999 & 10409.3 & 10859.1 & 6102.7 & 34513.5 & 31345.6 & 25034.7 & 19673.5 & 19533.5 & 12740.8 \\
2000 & 11947.5 & 11537.7 & 6701.9 & 36334.9 & 32592.8 & 26432.7 & 18250.3 & 20359.1 & 13645.7 \\
2003 & 14209.3 & 13785.3 & 8876.1 & 39496.4 & 36567.3 & 31112.9 & 24306.2 & 22985.1 & 16764.5 \\
2009 & 18291.9 & 19374.8 & 15569.3 & 47099.8 & 45660.6 & 43106.2 & 34035.8 & 28960.9 & 25303.6 \\
2016 & 27608.2 & 28184 & 29990.7 & 20196 & 58480.1 & 63057.6 & 32376.2 & 37304.2 & 40904.6 \\
2017 & 29742.8 & 29683.1 & 32935.2 & 59927.9 & 60529.6 & 66579 & 33873.2 & 38629.3 & 43809.8 \\
2018 & 31362.7 & 31249.5 & 36168.8 & 62641.0 & 62637.8 & 70297.1 & 36546.3 & 39989.8 & 46921.2 \\
\hline
\end{tabular}

* shows real data of GDP taken from World Bank [20] between the years 1960-2018.

\section{CONCLUSION}

We take into account GDP model with conformable derivative. Obtained results are evaluated by real data of Republic of Korea, European Union and United States of America from World Bank [20] between the years 1960-2018 by means of simulations, error analysis and efficiency.

We observe that the conformable GDP model (2) and integer order model (1) with real data of Republic of Korea in figure 1 and we analyze the results statistically in table 1. We examine the conformable GDP model (2) and integer order model (1) with real data of European Union in figure 2 and error margins and efficiency of models are given in table 2 . We analyze that the conformable GDP model (2) and integer order model (1) with real data of United States of America in figure 3 and the results are examined statistically in table 3. Finally, in table 4 , we give some real data and the results obtained from conformable and integer order models. From here, the efficiency of the conformable GDP model can be observed to the counterpart of the integer order. 
Consequently, results show that conformable derivative is more efficient for the GDP model on fitting real data than integer order counterpart.

\section{REFERENCES}

[1] Khalil, R., Horani, M.A., Yousef, A., \& Sababheh, M. (2014). A new definition of fractional derivative. Journal of Computational and Applied Mathematics, 264, 65-70.

[2] Abdeljawad, T. (2015). On conformable fractional calculus. Journal of Computational and Applied Mathematics, 279, pp. 57-66.

[3] Atangana, A., Baleanu, D., \& Alsaedi, A. (2015). New properties of conformable derivative. Open Mathematics, 13, (1).

[4] Bas, E., Acay, B., Ozarslan, R. (2019). The price adjustment equation with different types of conformable derivatives in market equilibrium. AIMS Mathematics, 4, (3), 805.

[5] Yusuf, A., Aliyu, A. I., \& Baleanu, D. (2018). Soliton solutions and stability analysis for some conformable nonlinear partial differential equations in mathematical physics. Optical and Quantum Electronics, 50, (4), 190.

[6] Ortega, A., Rosales, J. J. (2018). Newton's law of cooling with fractional conformable derivative. Revista mexicana de física, 64, (2), 172-175.

[7] Katugampola, U.N. (2014). A New Fractional Derivative with Classical Properties, arXiv:1410.6535v2.

[8] Anderson, D. R., Ulness, D. J. (2015). Newly defined conformable derivatives. Adv. Dyn. Syst. Appl, 10, (2), 109-137.

[9] Atangana, A., and Baleanu, D. (2016). New fractional derivatives with nonlocal and non-singular kernel: theory and application to heat transfer model. Thermal Science, 20, 757-763.

[10] Caputo, M., Fabrizio, M., (2015). A new definition of fractional derivative without singular kernel. Progress in Fractional Differentiation and Applications, 1, 1-13.

[11] Qureshi, S., Yusuf, A. (2019). Fractional derivatives applied to MSEIR problems: Comparative study with real world data. The European Physical Journal Plus, 134, (4), 171.

[12] Qureshi, S., Yusuf, A. (2019). Modeling chickenpox disease with fractional derivatives: From caputo to atangana-baleanu. Chaos, Solitons \& Fractals, 122, 111-118.

[13] Ozarslan, R., Ercan, A., Bas, E. (2019). Novel Fractional Models Compatible with Real World Problems. Fractal and Fractional, 3, (2), 15.

[14] Bas, E., Ozarslan, R. (2018). Real world applications of fractional models by Atangana-Baleanu fractional derivative. Chaos, Solitons \& Fractals, 116, 121-125.

[15] Bas, E., Metin, F. (2013). Fractional singular Sturm-Liouville operator for Coulomb potential. Advances in Difference Equations, 2013, (1), 300.

[16] Bas, E., Metin, F. (2015). Spectral analysis for fractional hydrogen atom equation. Advances in Pure Mathematics, 5, (13), 767.

[17] Almeida, R. (2017). What is the best fractional derivative to fit data?. Applicable Analysis and Discrete Mathematics, 11, (2), 358-368. 
[18] Bulut, H., Sulaiman, T. A., \& Baskonus, H. M. (2018). Dark, bright optical and other solitons with conformable space-time fractional second-order spatiotemporal dispersion. Optik, 163, 1-7.

[19] Yavuz, M., Yaşkıran, B. (2018). Homotopy methods for fractional linear/nonlinear differential equations with a local derivative operator. Balıkesir Üniversitesi Fen Bilimleri Enstitüsü Dergisi, 20, (3), 75-89.

[20] World Bank: World Development Indicators. (2019)

https://databank. worldbank.orgreports.aspx?source=2\&country=\&series=NY.GDP.PCAP.CD\&period=\#. Accessed 14 October 2019. 